\title{
INPUT-OUTPUT AGGLOMERATION: A TEMPORAL ANALYSIS
}

\author{
JOHN P. BLAIR *
}

Agglomeration economies were defined by Weber as: ${ }^{1}$

... a cheapening of production or marketing which results from the fact that production is carried on to some considerable extent at one place.

Such cost advantages are particularly significant in understanding the continued dominance of urban areas as locations for economic activity; agglomeration economies compensate for the higher labor and tax costs generally associated with urban enterprise. Yet, in spite of their importance, the nature of agglomeration economies is obscure. Bergsman and his associates observed that: ${ }^{2}$

Agglomeration forces, although fundamental to the growth process, are not well understood.

This paper attempts to clarify aspects of agglomeration. The thesis is that, because of a wide-spread neglect of the temporal dimension, the role of inputoutput linkages in the agglomeration process has been inadequately understood.

\section{Agglomeration via Input-Output Linkages}

The proposition that large input-output linkages are a determinant of industrial location was developed by Hirshman, Hoover and Isard, among others. ${ }^{3}$ The relationship between economic interdependence and input-output linkages is straightforward. Since the cells of an input-output table show the dollar amounts of transactions between industries, interindustry transactions reflect the tendency for geographic proximity between closely linked industries. Hoover summarized the causal relationship $:^{4}$

When outputs of an activity in a region are inputs to another activity, transfer costs are reduced by proximity of the two activities, and the presence of either of these activities in a region enhances to some degree the region's attractiveness as a location for the other activity.

Several recent studies have tested empirically the hypothesized relationship between input-output linkages and agglomeration. ${ }^{5}$ Although the studies made significant contributions to the literature, they neglected the temporal nature of agglomeration.

The empirical tests confirmed the theoretical implications. In general, they found that if industries $i$ and $j$ have large interindustry coefficients, then the geographic distribution of employment in the industries will be positively related;

*Assistant Professor, Department of Urban Affairs, University of Wisconsin, Milwaukee, Wisconsin 53201. I would like to thank Professor William H. Miernyk for comments on an early draft. 
cities with high (low) levels of employment in i will have high (low) levels of employment in $\mathrm{j}$. Confidence in the results is reinforced by the fact that the authors used different statistical techniques so that the findings are not sensitive to the empirical approach. ${ }^{6}$

\section{A Gap in the Literature}

The empirical tests of input-output agglomeration have been static; the distributions of total employment were analyzed but changes in employment overtime were ignored. Because of this neglect of time, the interpretations of the results are questionable. For example, after showing that input-output linkages are a determinant of the geographic association of industries, Richter stated: 7

The data and analysis used in this paper lead to the conclusion that industrial

linkages are agglomerating forces (italics added).

Similarly, the conclusion that input-output linkages are a determinant of the current changes in activity location is implicit in other studies.

The empirical studies were concerned with agglomeration regardless of how far in the past the location decision was made. Thus, the time horizon, although nowhere explicitly mentioned, spans decades. No attempt has been made to determine whether input-output linkages currently affect the geographic distribution of sectoral growth; we do not know whether linked industries grow in proximity. ${ }^{8}$ Only if the linkages affect the location of changes in output can we conclude that input-output linkages continue to be agglomerating forces.

The location pattern of the meat packing industry during the 1950's illustrates the gap. Prior to 1950 meat-packing was centered in the urban midwest. However, since then the industry has shifted to the cattle-raising areas of the plains. A static study analyzing meat-packing taken during the early 1950's would have suggested that backward linkages were not an important locational force since most of the industry's employment was in cities. Yet, the interindustry linkage of meat-packing with cattle-raising was the major current agglomerating factor.

The same reasoning may be applied to agglomeration in general. Industries may locate near linked industries early in their industrial life cycle in order to make use of possible technical advice from linked industries, a well developed labor force with related skills, and easy communications in addition to transportation cost savings. The diminished importance of agglomeration economies for mature industries would explain the observation that large urban areas are the birthplace of new industries, and that activities filter down as production becomes routinized. ${ }^{9}$ If proximity to linked industries is more important to developing than mature industries, then employment could be disproportionately located near linked activities, but changes in employment could be unaffected by interindustry transactions.

Finally, the increased footlooseness of economic activity resulting from decreased transportation costs is another possible factor in weakening once strong interindustry locational pulls. Total employment may remain predominantly near linked industries due to inertia or because of high relocation costs. However, new or relocating plants may be footloose. 
The neglect of time in the empirical studies can be attributed to previous theoretical work. Agglomeration theory has examined size and location of economic clusters at the expense of temporal questions. ${ }^{10}$ Thus no theoretical distinction exists between agglomeration resulting from past circumstances and the agglomerative forces which affect marginal location decisions.

\section{Empirical Evidence}

Are short term changes in employment in linked industries geographically proximate to each other to the same degree that total employment in linked industries is associated? In order to answer this question it is necessary to compare the static distribution of employment with changing associations between linked industries.

Changes in employment between 1958 and 1963 were calculated for the 51 manufacturing sectors in the input-output table of the United States for a sample of SMSAs. ${ }^{11}$ SMSAs were used as the geographic unit of analysis because they are integrated economic units rather than political subregions.

Correlation is the best measure of geographic association. If the short term changes in employment among sectors are correlated at the .05 significance level, they can be considered associated in growth. Likewise, if static employment for two sectors is correlated at the .05 level, they will be classified as associated..$^{12} \mathrm{By}$ comparing the proportion of sectors which are geographically associated between linked and non-linked sectors, the importance of interindustry transactions on location may be assessed.

After calculating the sector pairs which have static geographic associations, a chi-square test was used to determine whether total employment in linked sectors is more likely than non-linked sectors to be correlated over the sample of cities. Table 1 summarizes the results.

Table 1

STATIC GEOGRAPHIC ASSOCIATIONS OF EMPLOYMENT LINKED AND NON-LINKED SECTOR PAIRS

\begin{tabular}{lccrl}
\hline & Linked & Non-linked & Total & \\
\hline Geographically Associated & 44 & 89 & 133 & $\times^{2}=5.381$ \\
Not Geographically Associated & 217 & 925 & 1142 & $\mathrm{P}<.05$ \\
Total & 261 & 1014 & 1275 & \\
\% Associated & 16.8 & 8.8 & & \\
\hline
\end{tabular}

16.8 percent of the linked sectors were geographically associated whereas only 8.7 percent of the non-linked sectors were geographically associated. The difference in the proportion of associations is statistically significant at the .05 level. Input-output linkages have been agglomerating forces; the results are consistent with previous static studies.

Similarly, the geographic associations in employment changes for linked and non-linked sectors were calculated and are shown in Table 2. 
Table 2

\section{GEOGRAPHIC ASSOCIATIONS OF EMPLOYMENT CHANGES: LINKED AND NON-LINKED SECTOR PAIRS}

\begin{tabular}{lccrl}
\hline & Linked & Non-Linked & Total & \\
\hline Geographically Associated & 55 & 179 & 234 & $\times^{2}=1.19$ \\
Not Geographically Associated & 211 & 830 & 1041 & $\mathrm{P}>.10$ \\
\% Associated & .105 & .077 & & \\
\hline
\end{tabular}

From Table 2 it can be seen that the difference in proportion of associations in growth between linked and non-linked sectors is not significant. A comparison of changes in employment with the static results suggests that input-output agglomeration is not as strong a force over the short-term.

Two caveats should be noted in regard to the empirical findings. First, a five year time period was used. It is possible that an extension of the time horizon over which employment changes are measured will produce different results. Over such a short time period employment changes resulting from differential growth rates of existing plants will be relatively more important than relocation or births of new plants. Thus, excess capacity rather than the growth of proximate linked firms may determine changes in employment.

Second, the conclusion that agglomeration resulting from technological interdependence is more evident in static terms does not imply that input-output linkages are negligible factors for all sector pairs. An examination of interindustry coefficients greater than .0500 reveals that such industry pairs are more frequently associated in growth than other industries. The difference is significant at the .05 level.

\section{Policy Implications}

Knowledge of industrial linkages is an important policy tool for determining likely clusters of activities. With such knowledge, planners may determine which industries are likely to be attracted to an area in order to "link- up" with currently growing elements of a local economy. However, the efficacy of industrial linkages as agglomerating forces depends upon the time horizon. Short-term planning, such as strategies for dealing with business cycles, should have less emphasis upon growth via input-output agglomeration than long-range plans.

\section{FOOTNOTES}

1. Alfred Weber, Uber den Standort der Industries (Tubingen: J.C.B. Mohr, 1909), translated by C.J. Friedrick, Alfred Weber's Theory of the Location of Industries, (Chicago: University of Chicago Press, 1929), p. 126.

2. Joel Bergsman, Peter Greenstan, and Robert Healy, "Agglomeration Process in Urban Growth," Urban Studies, Vol. 9 (October 1972), p.263.

3. Albert O. Hirschman, The Strategy of Economic Development, (New Haven: Yale University Press, 1970), Chapter 5; E.M. Hoover, The Location of Economic Activity, (Cambridge, Massachusetts: MIT Press, 1956); and Walter Isard and Robert E. Kuenne, "The Impact of Steel upon the Greater New York-Philadelphia Industrial Region," The Review of Economics and Statistics, $X X X V$ (November 1953), pp. 289-301.

4. Edgar M. Hoover, An Introduction to Regional Economics, (New York: Alfred A. Knopf, 1971), p. 215.

5. Daryl A. Hellman, "A Model of Regional Export Activity," Growth and Change, Vol. 5 (January 1974), pp. 12-17; Leo H. Klaassen, Methods of Selecting Industries for Depressed Areas (Paris: OECD, 1967); M.E. Streit, "Spatial Association and Economic Linkages Between Industries," Journal of Regional Science, Vol. 9 (June 1969), pp. 177-193; Charles E. Richter, "The Impact of Industrial Linkages on Geographic Association," Journal of Regional Science, Vol. 9 (April 1963), pp. 101-128. 
6. The definition of linked industries is arbitrary. Leontief considers two sectors linked if the technical coefficient is $1 / \mathrm{n}$ or more. A similar definition is used in this study. Wassily Leontief et al., "The Structure of the U.S. Economy," Scientific American, Vol.212 (April 1965), pp. 25-35. The empirical techniques for quantifying the importance of I-O linkage differed in several important respects. For example, Richter correlated employment proportions between linked and non-linked sectors rather than absolute employment. Streit considered clusters of linked industries as well as linked pairs. Hellman, in a recent article, included the strength of the interindustry linkages as only one element in an estimating equation of various agglomerative economies. In each case, input-output linkages were shown to be a determinant of the locational proximity of linked industries.

7. Richter, op. cit., p. 27.

8. In this regard, Thompson observed: "We do not, however, have ... a locational matrix that tells us which industries follow a given industry to a locality and when." (Italics added.) Wilbur R. Thompson, "Internal and External Factors in the Development of Urban Economies" in Harvey S. Perloff and Lowden Wingo, Jr. (eds.), Issues in Urban Economics (Baltimore: Johns Hopkins Press, 1968), p.45.

9. Ibid., pp. 55-57.

10. Isard claimed that Marshall fostered an Anglo-Saxon bias by asserting that the influence of time is "more fundamental" than that of space. Ironically, much agglomeration theory characterizes the other extreme by neglecting time. Walter Isard, "The General Theory of Location and Space Economy," Quarterly Journal of Economics, Vol. 63 (November 1949), pp. 476-506.

11. In order to get the employment data at the SMSA level, it was necessary to estimate employment for some sectors from Location of Manufacturing Plants by County Industry and Employment Size. This publication gives the number of firms in 7 employment size classes by county at the 4 digit level. By multiplying the number of firms by the average size of each size class, employment in each industry may be estimated. For about half of the sectors, employment was gotten directly from the Census of Manufacturers, Vol. III. It was thus possible to gather employment for sectors in the 1963 input-output table published by the Department of Commerce (Survey of Current Business, November 1969).

12. Employment in sector $\mathrm{j}$ as a percentage of total employment was used as the static measure of activity rather than unadjusted employment since large cities may have higher total employment in all sectors. Thus the use of total employment rather than employment proportions may cause spurious correlations. 